\title{
Synchronverter-based Emulation and Control of HVDC transmission
}

\author{
R. Aouini, B. Marinescu, Member, IEEE, K. Ben Kilani, Member, IEEE, and M. Elleuch, Member, \\ IEEE
}

\begin{abstract}
This paper presents a new control strategy for High Voltage Direct Current (HVDC) transmission based on the synchronverter concept: the sending-end rectifier controls emulate a synchronous motor (SM), and the receiving end inverter emulates a synchronous generator (SG). The two converters connected with a DC line provide what is called a Synchronverter HVDC (SHVDC). The structure of the SHVDC is firstly analyzed. It is shown that the droop and voltage regulations included in the SHVDC structure are necessary and sufficient to well define the behavior of SHVDC. The standard parameters of the SG cannot be directly used for this structure. A specific tuning method of these parameters is proposed in order to satisfy the usual HVDC control requirements. The new tuning method is compared with the standard vector control in terms of local performances and fault critical clearing time (CCT) in the neighboring zone of the link. The test network is a 4 machine power system with parallel HVDC/AC transmission. The results indicate the contribution of the proposed controller to enhance the stability margin of the neighbour AC zone of the link.
\end{abstract}

Index Terms-- HVDC, synchronverter, synchronous generator/motor, regulator parameters tuning, residues, optimization.

\section{INTRODUCTION}

$\mathrm{H}$ IGH Voltage Direct Current (HVDC) systems uses direct current for bulk electric transmission power based on high power electronics which provide the opportunity to enhance controllability, stability and power transmission capability of AC transmission systems [1]. Practical conversion of power between AC and DC became possible with the development of power electronics devices such as thyristors and Voltage Source Converters (VSC). The VSC technology offers even more flexibility, new capabilities for dynamic voltage support, independent controls of active/reactive power and easier integration of wind farms [2]. These HVDC transmission systems are specifically used to connect asynchronous grids, as for example the EnglandFrance interconnection [3]. Nonetheless, other equally important HVDC applications concern complex AC interconnected systems in order to enhance the power transmission capacity and meet the growing demand.

The planned Spain-France interconnection [4], which will use the VSC technology scaled up to $2000 \mathrm{MW}$, is such an example. These emerging applications gave rise to the coexistence of parallel HVDC/HVAC, and consequently, an increased level of $\mathrm{AC} / \mathrm{DC} / \mathrm{AC}$ converted power injected into AC networks.

Many studies have shown that the methods of controlling HVDC converters have an impact on stability of the system in which the link is inserted. The main trend in control techniques for VSC HVDC links are based on the well established vector control scheme. For example, in [5] the standard vector control has been modified to improve the dynamic performance of a parallel AC/DC interconnection. In [6] the VSC-HVDC operating characteristics are determined by a decoupled PI controller to provide decoupled and independent control of the active and reactive powers for each converter. Generally, and due to their simple structure and robustness, PI controllers have been adjusted to meet HVDC specifications. For example, the authors in [7] proposed a robust control scheme for a parallel AC/DC system. In [8], an adaptive optimal control was developed for an HVDC system.

Recently, in [9]-[14], the authors have proposed a different control method for which an inverter can be operated to mimic the behavior of a synchronous generator (SG) and the resulting closed-loop has been called a synchronverter [9]. Since the operation of AC systems via SGs voltage/frequency regulation is rather well known [15], the synchronverter concept led to new applications. For example, in [16], a STATCOM controller was synthesized from the mathematical model of synchronous generators operated in a compensator mode.

In this work, the synchronverter concept is adapted to converters of an HVDC transmission. The idea is a conceptual control strategy of the DC line, where the sending-end rectifier controls emulate a synchronous motor (SM), and the receiving end inverter emulates a SG, both along with their controls. This resulting Synchronverter based HVDC will be called SHVDC in the paper. It is shown that the parameters usually used for the regulations of the SG of the same capacity cannot be directly used for the SHVDC. This led us to propose a tuning method of the HVDC converters parameters in order to satisfy both the local HVDC control requirements and to improve the transient stability of the neighbor AC zone of the HVDC link. The rest of the paper is organized as follows: in Section II, the conventional modeling and control of an HVDC-VSC transmission system is briefly overviewed. The synchronverter concept is extended in Section III to the case of an HVDC link. In Section IV, the SHVDC structure 
proposed in Section III for the HVDC link is analyzed from a structural point of view. An analytic method to tune the parameters of the controllers of the SHVDC in order to meet the desired performances is given in Section V, while validation tests are presented in Section VI.

\section{Conventional Modeling And Control Of An HVdC- VSC TRANSMISSION SYSTEM}

An HVDC system consists of three parts: a rectifier station, an inverter station and a high-voltage DC transmission line as shown in Fig. 1. Each converter is connected to the AC network via a grid impedance $Z_{g}$ representing the short-circuit power at the connection point.

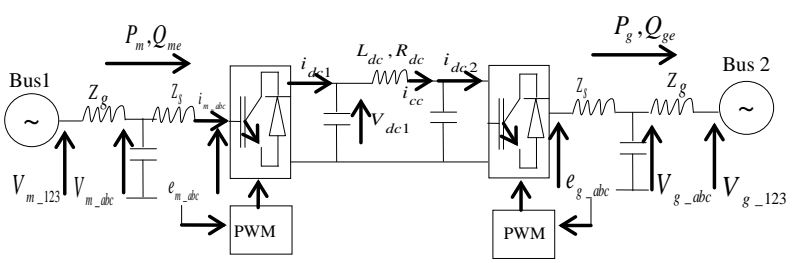

Fig. 1. Two terminal HVDC-VSC link

For its advantage on control capability, the VSC technology is assumed. Each converter holds two degrees of freedom for the control. Usually, these degrees are used for the control of the reactive power at each side, of the active power and for the DC voltage [6]. Each station controls its reactive power independently of the other station. The flow of active power in the DC transmission system must be balanced, which means that the active power entering the HVDC system must mutch the active power leaving it, plus the losses in the DC transmission system. To achieve this power balance, one of the stations has to control the active power, while the other station should be designed for the DC voltage control. Usually, the two converters of an HVDC are controlled by two independent loops and each of these controls is based on the vector control approach in the $\mathrm{d}-\mathrm{q}$ frame, using cascaded PI controllers [2]: the outer control loop generates the respective $\mathrm{d}-\mathrm{q}$ current references to the inner current control loop.

\section{SYNCHRONVERTER-BASED HVDC}

In this section, a control strategy based on synchronverter technology is adapted for HVDC-VSC converters where the HVDC converters are run as synchronous machines. The synchronverter proposed in [9] is an inverter that mimics the structure and the regulations of a synchronous generator (SG). The usual control strategies used for conventional SG can thus be used for the inverter. For a complete DC system, a rectifier and an inverter are bound by a DC link. Therefore, to provide an HVDC structure, another synchronverter working as a synchronous motor (SM) based on the same mathematical derivation is necessary. As a result, the DC power is sent from the SM to the SG. Firstly, an overview of the synchronverter concept is presented, where the inverter is modeled according the mathematical model of a SG.

Next, the synchronverter concept is extended to a rectifier that mimics a SM.

\section{A. Overview of the synchronverter concept}

A synchronverter is an inverter which regulations are chosen such that the resulting closed-loop mimics the behavior of a conventional SG. For the purpose of the development, we recall the structure of a three phase round rotor synchronous machine [15] as shown in Fig. 2.

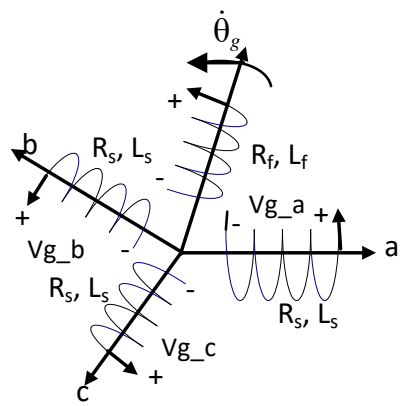

Fig. 2. Structure of an idealized three-phase round-rotor SG

The stator windings can be seen as concentrated coils having self-inductance $L$ and mutual inductance $(-M)$ ). The field winding can be seen as a concentrated coil having a selfinductance $L_{f}$. The phase terminal voltage vector $V_{g_{-} a b c}=\left[V_{g a} V_{g b} V_{g c}\right]^{T}$ may be expressed by

$$
V_{g_{-} a b c}=-R_{s} i_{g_{-} a b c}-L_{s} \frac{d i_{g_{-} a b c}}{d t}+e_{g_{-} a b c},
$$

where $i_{g_{-} a b c}=\left[\begin{array}{lll}i_{g a} & i_{g b} & i_{g c}\end{array}\right]^{T}$ is the stator phase currents vector, $L_{s}=L+M, R_{s}$ are, respectively, the inductance and the resistance of the stator windings. The back emf vector $e_{g_{-} a b c}=\left[\begin{array}{lll}e_{g a} & e_{g b} & e_{g c}\end{array}\right]^{T}$ is the back emf given by

$$
e_{g_{-} a b c}=M_{g} s \theta_{g} \tilde{\sin } \theta_{g},
$$

where $M_{g}$ is the flux field, $\theta_{g}$ is the electric rotor angle and

$$
\tilde{\sin } \theta_{g}=\left[\sin \theta_{g} \sin \left(\theta_{g}-\frac{2 \pi}{3}\right) \sin \left(\theta_{g}+\frac{2 \pi}{3}\right)\right]^{T},
$$

The mechanical equation of the machine is given by

$$
J_{g} \ddot{\theta}_{g}=T_{g m}-T_{g e}-D_{g p} s \theta_{g},
$$

where $J_{g}$ is the combined moment of inertia of generator and turbine, $T_{g m}$ is the mechanical torque, $T_{g e}$ is the electromagnetic torque and $D_{g p}$ is a damping factor. The torque $T_{g e}$ is given by

$$
T_{g e}=M_{g}<i_{g_{-} a b c}, \tilde{\sin } \theta_{g}>,
$$

where the operator $<$... $>$ denotes the conventional inner product in $\mathbb{R}^{3}$.

The real and reactive powers generated by the SG are, respectively

$$
\begin{aligned}
& P_{g}=M_{g} s \theta_{g}<i_{g_{-a b c}}, \tilde{\sin } \theta_{g}>, \\
& Q_{g e}=-M_{g} s \theta_{g}<i_{g_{-} a b c}, \cos \theta_{g}>.
\end{aligned}
$$

Based on the SG model above (Eq. 1-7), the concept of synchronverter is developed. The latter consists of an inverter on which specific controls are built and structured, as shown in Fig. 3. On the figure, we depict (i) the power 
part consisting of the inverter plus the LC filter and (ii) controls assured by the electronic part.

Such control structure is shown to be equivalent to a SG with capacitor bank connected in parallel with the stator terminal [9]. More specifically, with the terminal voltages $V_{g_{-} a b c}$ and the voltages $e_{g_{a} a b c}$ defined on the Fig. 3 , the voltage equation (1) holds. The voltage $e_{g_{-} a b c}=\left[\begin{array}{lll}e_{g a} & e_{g b} & e_{g c}\end{array}\right]^{T}$ corresponds to the back emf of the virtual rotor. The inverter switches are operated so that the average values of $e_{g_{-} a}$, $e_{g_{-} b}$ and $e_{g_{-} c}$ over a switching period are to be equal to $e_{g_{-} a b c}$ given in (2). This can be achieved by the usual PWM technique. It's worth noting that the VSC technology used in this work is not exclusive. However, it is suited for generating pulse control signals. The electronic part controls the switches in the power part. These two parts interact via the signals $e_{g_{-} a b c}$ and $i_{g_{-} a b c}$.

The synchronverter given in Fig. 3 is connected to the grid via the impedance ( $L_{g}, R_{g}$ ), thus, its output current and voltage may be given by

$$
\begin{aligned}
& V_{g_{-} a b c}=\frac{1}{C_{f} s}\left(i_{g_{-} a b c}-i_{g_{-} 123}\right), \\
& i_{g_{-} 123}=\frac{1}{\left(R_{g}+L_{g} s\right)}\left(V_{g_{-} a b c}-V_{g_{-} 123}\right) .
\end{aligned}
$$

We may write a swing equation for the synchronverter, similar to equation (3):

$$
\ddot{\theta}_{g}=\frac{1}{J_{g}}\left(T_{g m}-T_{g e}-D_{g p} s \theta_{g}\right),
$$

where the mechanical torque $T_{g m}$ is a control input, $\theta_{g}$ is the angle position of the synchronverter. The electromagnetic torque $T_{g e}$ depends on $i_{g_{-} a b c}$ and $\theta_{g}$.

To mimic the droop of the SG, the following frequency droop control loop is proposed

$$
T_{g m}=T_{g m-r e f}+D_{g p}\left(\omega_{n}-s \theta_{g}\right) .
$$

The synchronverter thus shares load with the other generators of the AC grid to which it is connected in proportion with the static droop coefficient $D_{g p}$. In (10), $T_{g m-r e f}$ is the mechanical torque applied to the rotor and it is generated by a PI controller as shown in Fig. 3 to regulate the real power output $P_{g}$

$$
T_{g m_{-} \text {ref }}=\left(K_{p_{-} p_{g}}+\frac{K_{i_{-} p_{g}}}{s}\right)\left(P_{g}-P_{g_{-} \text {ref }}\right) .
$$

The reactive power $Q_{g}$ is controlled by a voltage droop control loop using a voltage droop coefficient $D_{g q}$, in order to regulate the field excitation $M_{g}$, which is proportional to the voltage generated following (12) and (13)

$$
M_{g}=\frac{1}{k_{g} S}\left(Q_{g m}-Q_{g e}\right),
$$

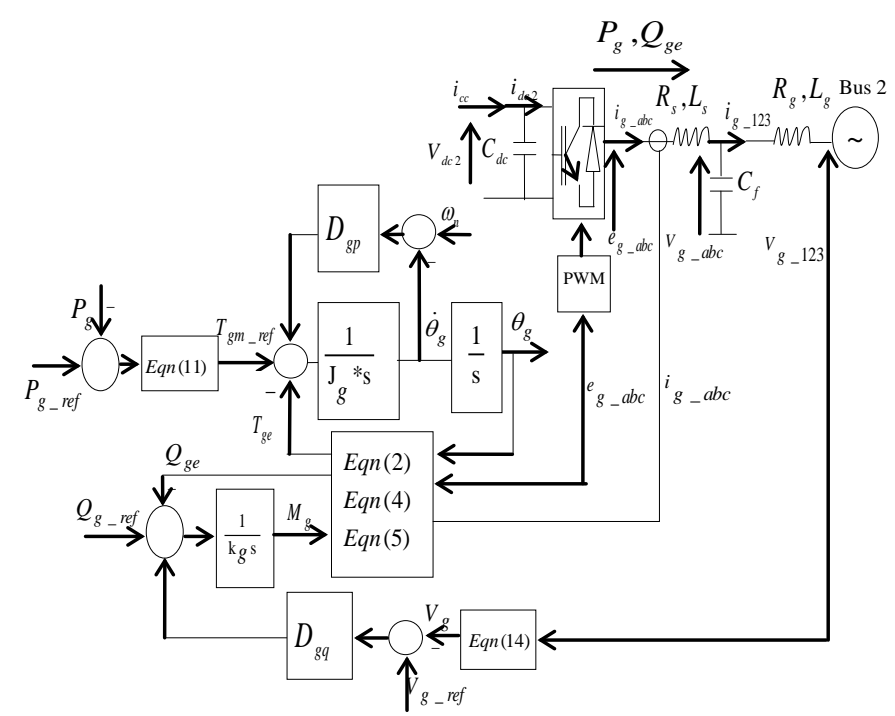

Fig. 3. Model of the synchronverter: power and electronic parts [9]

$$
Q_{g m}=Q_{\text {g_ref }}+D_{g q}\left(V_{g_{-} \text {ref }}-V_{g}\right),
$$

where $V_{g}$ is the output voltage amplitude computed by

$$
V_{g}=\frac{2}{\sqrt{3\left(V_{g a} V_{g b}+V_{g a} V_{g c}+V_{g b} V_{g c}\right.}} .
$$

\section{B. Extension of the synchronverter concept to the HVDC emulation}

To obtain an HVDC transmission system, in addition to a SG emulated by a synchronverter as in the section above, a rectifier that mimics a SM and a DC line are needed. The resulting system, a SM/SG and a DC line are called Synchronverter High-Voltage Direct Current (SHVDC).

\section{B.1. The synchronverter model of a SM}

The synchronverter model of a SM consists of an LC filter and mainly controls shown in the same Fig. 3. It's nearly the same model discussed above, apart from the fact that the sign convention for the stator current $i_{m_{-} a b c}=\left[\begin{array}{lll}i_{m a} & i_{m b} & i_{m c}\end{array}\right]^{T}$ is changed. Equations (1), (4), (8) and (9) are re-written in motor convention

$$
\begin{aligned}
& V_{m_{-} a b c}=R_{s} i_{m_{\_} a b c}+L_{s} \frac{d i_{m_{\_} a b c}}{d t}+e_{m_{-} a b c}, \\
& \ddot{\theta}_{m}=\frac{1}{J_{m}}\left(T_{m e}-T_{m m}-D_{m p} \dot{\theta}_{m}\right), \\
& V_{m_{-} a b c}=\frac{1}{C_{f} s}\left(i_{m_{-} 123}-i_{m_{-} a b c}\right), \\
& i_{m_{-} 123}=\frac{1}{\left(R_{g}+L_{g} s\right)}\left(V_{m_{-} 123}-V_{m_{-} a b c}\right) .
\end{aligned}
$$

The bloc equations (2), (5) and (7) remain the same

$$
\begin{gathered}
e_{m_{-} a b c}=M_{m} s \theta_{m} \tilde{\sin } \theta_{m}, \\
T_{m e}=M_{m}<i_{m_{-} a b c}, \sin \theta_{m}>, \\
Q_{m e}=M_{m} s \theta_{m}<i_{m_{-} a b c}, \cos \theta_{m}>, \\
P_{m}=M_{m} s \theta_{m}<i_{m_{-} a b c}, \tilde{\sin } \theta_{m}>.
\end{gathered}
$$

The frequency and the voltage droop controls are also similar to the SG emulation case; except for the power regulation (11) which is replaced by the DC voltage control loop as defined by (24) 


$$
\begin{gathered}
T_{m m}=T_{m m-r e f}+D_{m p}\left(\omega_{n}-s \theta_{m}\right), \\
T_{m m-r e f}=\left(K_{p_{-} v d c}+\frac{K_{i_{-} v d c}}{s}\right)\left(V_{d c_{-} \text {ref }}-V_{d c l}\right), \\
Q_{m m}=Q_{m_{\_} \text {ere }}+D_{m q}\left(V_{m_{-} \text {ref }}-V_{m}\right), \\
M_{m}=\frac{-1}{k_{m} s}\left(Q_{m m}-Q_{m e}\right), \\
V_{m}=\frac{2}{\sqrt{3\left(V_{m a} V_{m b}+V_{m a} V_{m c}+V_{m b} V_{m c}\right.}} .
\end{gathered}
$$

\section{B.2. Coupling equations}

The circuit equations of the DC line (Fig. 1 \& 3) are

$$
\begin{gathered}
V_{d c 1}=\frac{1}{C_{d c} s}\left(i_{d c 1}-i_{c c}\right), \\
V_{d c 2}=\frac{1}{C_{d c} s}\left(i_{c c}-i_{d c 2}\right), \\
i_{c c}=\frac{1}{L_{d c} s}\left(V_{d c 1}-V_{d c 2}-R_{d c} i_{c c}\right) .
\end{gathered}
$$

The AC and DC circuits are coupled by the active power relation

$$
\begin{gathered}
P_{d c 1}=V_{d c 1} i_{d c 1}, \\
P_{d c 2}=V_{d c 2} i_{d c 2}, \\
P_{d c 1}=P_{m}, \\
P_{d c 2}=P_{g} .
\end{gathered}
$$

IV. StRuctural ANALYSis Of SyNCHRONVERTERs BASED HVDC

In this section, the SHVDC is analyzed from a structural point of view. More precisely, the droop and voltage regulations introduced in [9] for the synchronverter in Fig. 3 are appropriate in the sense that they cancel all the degrees of freedom of the system, so that, with given initial conditions, the trajectories of the closed-loop system in Fig. 3 are uniquely defined. Roughly speaking, the number and the nature of the regulations are necessary and sufficient for this system. When coupling two synchronverters as in Section II to form the SHVDC, this fact is not obvious. Moreover, controls for the power exchange and the DC voltage have been added by equations (11) and respectively (24). The scope of this section is to prove that the proposed structure is well-defined from the point of view mentioned above. As the model of the SHVDC is given by equations (1)-(34) in a general Differential Algebraic Equations (DAE) form, the approach introduced in [17] and related references can be directly used. In this latter, a linear system $\Sigma$ is a module $M$ defined by a matrix equation

$$
S(s) w=0,
$$

where $S(s)$ is a matrix which elements are polynomials in the derivation operator $s=d / d t$. For the SHVDC, $w$ is given by (36), and $s(s)$ results from the linear approximation of equations (1)-(34). Let $\mathrm{k}=$ length ( $\mathrm{w}$ ) and $\mathrm{r}=\mathrm{rank}(\mathrm{S}(\mathrm{s})$ ).

$$
\begin{aligned}
& \mathrm{w}=\left[\mathrm{i}_{\mathrm{g} \_a b c}, \mathrm{~V}_{\mathrm{g} \_a b c}, \mathrm{e}_{\mathrm{g} \_ \text {abc }}, \mathrm{i}_{\mathrm{g} \_123}, \mathrm{i}_{\mathrm{m} \_a b c}, \mathrm{~V}_{\mathrm{m} \_a b c}, \mathrm{e}_{\mathrm{m} \_ \text {abc }}, \mathrm{i}_{\mathrm{m} \_123}, \mathrm{P}_{\mathrm{g}}\right. \text {, } \\
& \mathrm{T}_{\mathrm{ge}}, \mathrm{T}_{\mathrm{gm}}, \mathrm{T}_{\mathrm{gm} \_ \text {ref }}, \theta_{\mathrm{g}}, \mathrm{P}_{\mathrm{m}}, \mathrm{T}_{\mathrm{me}}, \mathrm{T}_{\mathrm{mm}}, \mathrm{T}_{\text {mm_ref }}, \theta_{\mathrm{m}}, \mathrm{Q}_{\mathrm{ge}}, \mathrm{Q}_{\mathrm{gm}}, \mathrm{M}_{\mathrm{g}}, \mathrm{V}_{\mathrm{g}} \text {, } \\
& \left.\mathrm{V}_{\mathrm{dc} 1}, \mathrm{i}_{\mathrm{dc} 1}, \mathrm{P}_{\mathrm{dc} 1}, \mathrm{Q}_{\mathrm{me}}, \mathrm{Q}_{\mathrm{mm}}, \mathrm{M}_{\mathrm{m}}, \mathrm{V}_{\mathrm{m}}, \mathrm{V}_{\mathrm{dc} 2}, \mathrm{i}_{\mathrm{dc} 2}, \mathrm{i}_{\mathrm{cc}}, \mathrm{P}_{\mathrm{dc} 2}, \sin \theta_{g}\right]^{\mathrm{T}}
\end{aligned}
$$

From [17], the integer $k=m-r$ is the rank of the module $M$ , which coincides with the rank of the linear system $\Sigma$.

The number of the independent inputs $u=\left\{u_{1} . . u_{m}\right\}$ of the system $M$ given by (35) is the rank of the module which defines the system $m=r a n k(M)$. For the SHVDC case, the rank of the module $\mathrm{M}$ defined by the SHVDC is zero, which means that the regulations included in (1)-(34) are necessary and sufficient to well define the behavior of this structure. The choice of the regulations parameters in order to ensure stability and desired performances is next discussed.

\section{TUNing Of A SYNCHRONVERTER BASED HVDC}

The SHVDC structure is investigated in this section on the simple system of Fig. 1. A four machines system will be used in Section VI. The simulations tool in the Matlab/Simulink toolbox.

A. Tuning with standard parameters of classic SG

The main advantage of the synchronverter is to put into evidence the structure of classic generators for which the controls are well known. For this reason, we firstly adopted for the new SHVDC structure standard parameters of a SG which are given in the first column of Table III. They mainly correspond to $5 \%$ governor droop [15] $\left(1 / \mathrm{D}_{\mathrm{gp}}\right.$ and $\left.1 / \mathrm{D}_{\mathrm{mp}}\right)$ and a $3 \%$ AVR gain $\left(1 / \mathrm{D}_{\mathrm{gq}}\right.$ and $\left.1 / \mathrm{D}_{\mathrm{mq}}\right)$ [18]. The responses of the SHVDC to step changes in active/reactive power references are given in Fig. 4 in solid lines in comparison with the ones in dotted lines obtained with a classic vector control (see, e.g., [19]). Although the voltage and reactive power dynamics are quite similar, a poorly damped response is obtained for the active power $\mathrm{P}$ with the SHVDC. As a consequence, the usual parameters of a synchronous generator of the same capacity cannot be directly used for the SHVDC and a specific tuning of the parameters of the latter was done as presented in the next section.

B. Specific framework for the tuning of the SHVDC parameters

B.1. HVDC control specifications: we first recall the usual full set of control specifications for a VSC based HVDC, as presented in Section II. Set-points for the transmitted active power, the reactive power and the voltage at the points of coupling have to be tracked with the following transient performances $[6,20]$ :

- the response time of the active/reactive power is normally in the range of $50 \mathrm{~ms}$ to $150 \mathrm{~ms}$.

- the response time for voltage is about $100 \mathrm{~ms}$ to $500 \mathrm{~ms}$.

The dynamic of the HVDC should also improve the stability of the neighboring (see, e.g., [5]). 
(a)

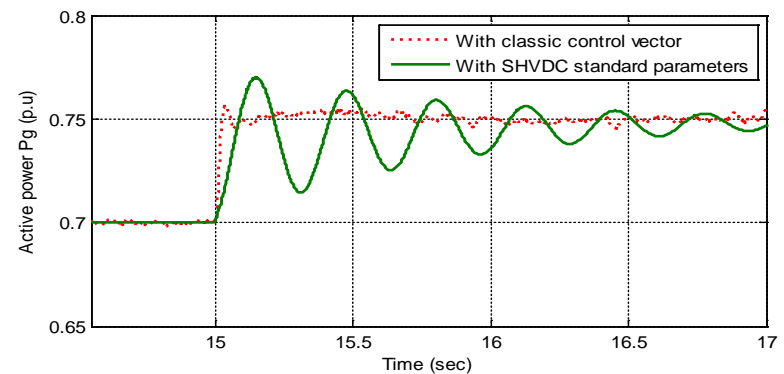

(b)

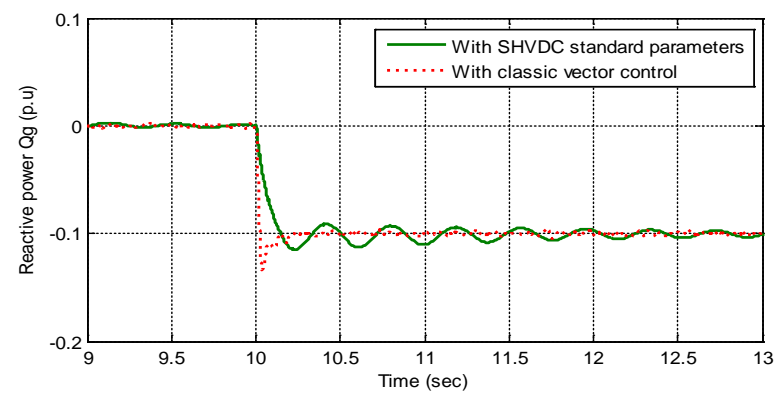

(c)

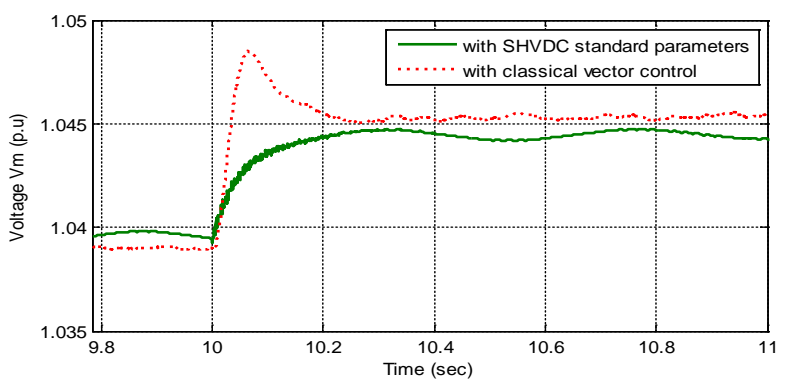

(d)

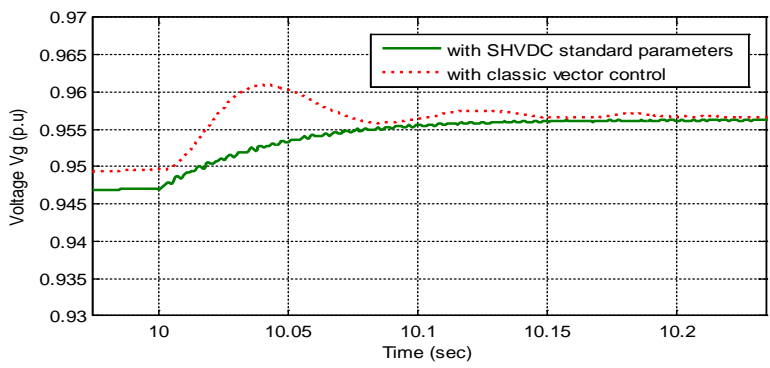

(e)

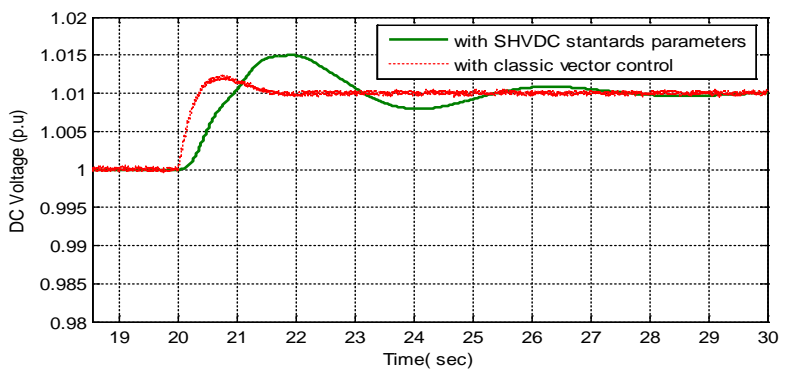

Fig. 4. Responses with standard SG parameters. (a) Response of $P_{g}$ to a +0.05 step in $P_{g_{-} \text {ref }}$ (p.u) ; (b) Response of $Q_{g}$ to a -0.1 step in $Q_{g_{-} \text {ref }}$ (p.u); (c) Response of $V_{g}$ to a -0.1 step change in $Q_{g_{-} \text {ref }}$ (p.u); (d) Response of $V_{m}$ to a -0.1 step change in $Q_{m_{\text {_ref }}}$ (p.u); (e) Response of $V_{d c}$ to a +0.01 step in $V_{d c_{-} r e f}$ (p.u).
B.2. Control structure: in order to satisfy these specifications, the SHVDC parameters should be tuned simultaneously and in a coordinated way. For this tuning, the SHVDC shown in Fig. 1 is put into the feedback system structure presented in Fig. 5 where $\tilde{\Sigma}$ is modeled by equations (1) to (34) with the exception of equations (10), (11), (13), (24), (25) and (26). All control parameters are grouped in the following diagonal matrix

$$
\mathrm{K}(\mathrm{s}, \mathrm{q})=\operatorname{diag}\left(\mathrm{D}_{\mathrm{gp}}, \mathrm{D}_{\mathrm{mp}}, \mathrm{K}_{\mathrm{p} \_\mathrm{Vdc}}, \mathrm{K}_{\mathrm{i}-\mathrm{Vdc}}, \mathrm{D}_{\mathrm{gq}}, \mathrm{D}_{\mathrm{mq}}, \mathrm{K}_{\mathrm{p} \_\mathrm{pg}_{\mathrm{g}}}, \mathrm{K}_{\mathrm{i}-\mathrm{p}_{\mathrm{g}}}\right) \text {. }
$$

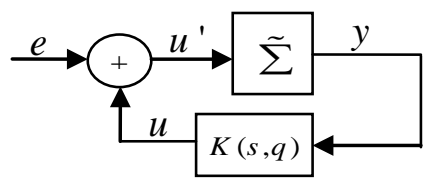

Fig. 5. Feedback system

where $D_{g p}, D_{m p}$ are, respectively, the static frequency droop coefficients of the SG and the SM; $D_{g q}, D_{m q}$ are, respectively, the voltage droop coefficient of the SG and of the SM; $K_{p V_{d c}}, K_{i V_{d c}}$ are the DC voltage PI control parameters; and $K_{p_{-} P_{q}}, K_{i_{-} P_{q}}$ are the active power PI control parameters.

Note that all elements of the matrix $K(s, q)$ are tuned via the pole placement presented in Section V.B.3 to meet HVDC performance specifications given in Section V.B.1.

The inputs $\mathrm{u}$ and the outputs $\mathrm{y}$ are

$\mathrm{u}=\left[\mathrm{T}_{\mathrm{mm}}, \mathrm{Q}_{\mathrm{mm}}, \mathrm{T}_{\mathrm{mm}-\mathrm{ref} \_\mathrm{kp}}, \mathrm{T}_{\mathrm{mm}-\text { ref_ki }}, \mathrm{T}_{\mathrm{gm}}, \mathrm{Q}_{\mathrm{gm}}, \mathrm{T}_{\mathrm{gm}-\mathrm{ref} \_\mathrm{kp}}\right.$,

$\left.\mathrm{T}_{\mathrm{gm}-\mathrm{ref} \_k i}\right]^{\mathrm{T}}$

$\mathrm{y}=\left[\omega_{n}-\mathrm{s} \theta_{\mathrm{m}}, \mathrm{V}_{\mathrm{m} \_ \text {ref }}-\mathrm{V}_{\mathrm{m}}, \mathrm{V}_{\mathrm{dc} \_ \text {ref }}-\mathrm{V}_{\mathrm{dc}}, \frac{\mathrm{V}_{\mathrm{dc} \_ \text {ref }}-\mathrm{V}_{\mathrm{dc}}}{\mathrm{s}}, \omega_{n}-\mathrm{s} \theta_{\mathrm{g}}\right.$,

$\left.\mathrm{V}_{\mathrm{g} \_ \text {ref }}-\mathrm{V}_{\mathrm{g}}, \mathrm{P}_{\mathrm{g} \_ \text {ref }}-\mathrm{P}_{\mathrm{g}}, \frac{\mathrm{P}_{\mathrm{g} \_ \text {ref }}-\mathrm{P}_{\mathrm{g}}}{\mathrm{S}}\right]^{T}$.

B.3. Regulator parameters and residues: let $H(s)$ be the transfer matrix of a linear approximation of $\tilde{\Sigma}$ and consider each closed-loop of the feedback system in Fig. 5 which corresponds only to input $u_{i}$ and output $y_{i}$

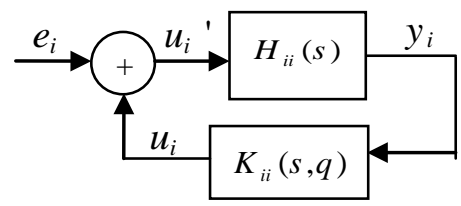

Fig. 6. Single input/Single output feedback system

More specifically, $H_{i i}(s)$ and $K_{i i}(s)$ are the (i,i) transfer functions of $\mathrm{H}(\mathrm{s}), K(s, q)$, respectively.

Proposition (e.g., [21]): The sensitivity of a pole $\lambda$ of the closed-loop in Fig. 6 with respect to a parameter $q$ of the regulator $K_{i i}$ is

$$
\frac{\partial \lambda}{\partial q}=r_{\lambda} \frac{\partial K_{i i}(s, q)}{\partial q}
$$

where $r_{\lambda}$ is the residue of $H_{i i}(s)$ at pole $\lambda$. 
Note that, for our case. (37), $\left.\frac{\partial K_{i i}(s, q)}{\partial q}\right|_{s=\lambda}=1$.

Also, the poles of $H_{i i}(s)$ are among the poles of $H(s)$. As a consequence, the residues of the linear approximation of $\tilde{\Sigma}$ can be used for the pole placement as shown in Section V.D. Before, some basic notions of modal analysis are recalled.

\section{Modal analysis of the system}

This analysis is based on a state representation of the transfer matrix $H(s)$ of the form

$$
\Sigma: \quad \dot{\mathrm{x}}=\mathrm{A} \mathrm{x}+\mathrm{B} u, y=\mathrm{C} \mathrm{x} .
$$

The poles $\lambda_{i}$ of $H(s)$ correspond to the eigenvalues (modes) of A. The participation factors measure the relative participation of the $\mathrm{k}^{\text {th }}$ state variable in the $\mathrm{i}^{\text {th }}$ mode:

$$
p_{k i}=\psi_{i k} * \varphi_{k i} \text {, }
$$

where $\varphi_{i}$ and $\psi_{i}$ are respectively the right and the left eigenvectors of $A$ associated with the mode $\lambda_{i}$. They are given in Table II for system (39).

Each element $H_{i j}(s)$ of $H(s)$ can be expanded in partial fractions as

$$
H_{i j}(s)=\sum_{k=1}^{k=n} \frac{r_{k}}{s-\lambda_{k}},
$$

where $\mathrm{r}_{\mathrm{k}}$ is the residue of $H_{i j}(s)$ at pole $\lambda_{i}$ expressed as

$$
r_{k}=C_{i} \varphi_{k} \psi_{k} B_{j},
$$

where $C_{i}$ is the $\mathrm{i}^{\text {th }}$ line of $C$ and $B_{j}$ is the $\mathrm{j}^{\text {th }}$ column of $B$ [21].

\section{Coordinated tuning of SHVDC parameters}

First, desired locations $\lambda_{i}^{*}$ can be computed for each pole $\lambda_{i}$ starting from the control specifications given in Section B.1. To ensure a second order type response without overshoot, the damping of the corresponding complex mode $\lambda_{i}$ is imposed to be $\zeta_{i}=0.7$. The frequency of the mode is deduced from the desired response time $t_{r}$ given in Section B.1: $\omega_{i 0}=3 / t_{r} \quad$ [21]. Thus, the desired location of $\lambda_{i}$ is $\lambda_{i}^{*}=-\zeta_{i} \omega_{i 0} \pm j \omega_{i 0} \sqrt{1-\zeta_{i}^{2}}$ and the results for the dynamics of interest for the SHVDC are given in Table I (column 3).

It should be noted that, the dynamic of reactive power is the same as the dynamic of the voltage. The connections in Table I between the dynamics of interest and the modes are established based on the participations factors given in Table II. Only the highest participation factor is considered, therefore each dynamic is associated to only one pole for the computation of desired poles $\lambda_{i}^{*}$. However, from the same column of Table II; several poles have also significant participations to the same dynamic which led us to compute the gains $K$ in a coordinated way. More specifically, if $\Lambda$ denotes the set indices j from 1 to 8 for which $H_{j j}(s)$ has $\lambda_{1}$ as pole, the contribution of each control gain in the shift of the pole is

$$
\lambda_{\imath}=\lambda_{\imath}^{0}+\sum_{j \in \Lambda} r_{i j} K_{j}
$$

where $\lambda_{i}^{0}$ is the initial (open-loop) location of the pole $\lambda_{i}$ and $r_{i j}$ is the residue of $H_{i j}(s)$ in $\lambda_{i}$. Finally, the pole placement is the solution of the following optimization problem

$$
\left\{K_{j}^{*}, j=1 \ldots 8\right\}=\underset{K_{j}}{\arg \min } \sum_{i}\left\|\lambda_{i}^{*}-\lambda_{i}\right\|^{2},
$$

where $\lambda_{i}$ is given by (43).

TABLE I

DESIRED MODES MEETING THE HVDC SPECIFICATIONS

\begin{tabular}{lccc}
\hline $\begin{array}{l}\text { Dynamics of } \\
\text { interest }\end{array}$ & $\lambda_{i}^{0}$ & $\lambda_{i}^{*}$ & $r_{\lambda_{i}^{0}}$ \\
\hline Voltage $V_{m}$ & -3.8713 & -10 & -0.543 \\
Voltage $V_{g}$ & 3.537 & -10 & -0.65 \\
Active Power $P_{m}$ & $1.8 \pm 5.89 \mathrm{i}$ & $-21 \pm 21.42 \mathrm{i}$ & $-0.06 \pm 0.01 \mathrm{i}$ \\
Active Power $P_{g}$ & $-3.3 \pm 10.3 \mathrm{i}$ & $-21 \pm 21.42 \mathrm{i}$ & $-0.06 \pm 0.1 \mathrm{i}$ \\
Reactive Power $Q_{m}$ & -3.8713 & -10 & -0.543 \\
Reactive Power $Q_{g}$ & 3.537 & -10 & -0.65 \\
\hline
\end{tabular}

TABLE II

PARTICIPATION FACTORS

\begin{tabular}{lcccc}
\hline$\%$ & $P_{a_{-} V_{m} / Q_{m}}$ & $P_{a_{-} V_{g} / Q_{g}}$ & $P_{a_{-} P_{m}}$ & $P_{a_{-} P_{g}}$ \\
\hline$\lambda_{V_{m} / Q_{m}}^{0}$ & 57 & 2.1 & 21.8 & 28 \\
$\lambda_{P_{m}}^{0}$ & 0.2 & 71.9 & 0.3 & 15.8 \\
$\lambda_{V_{g} / Q_{g}}^{0}$ & 21.7 & 7.6 & 40 & 2.2 \\
$\lambda_{P_{g}}^{0}$ & 1.8 & 14 & 1.7 & 42.8 \\
\hline
\end{tabular}

TABLE III

SHVDC PARAMETERS

\begin{tabular}{lcc}
\hline$K$ & $\begin{array}{c}\text { SHVDC standard } \\
\text { parameters }\end{array}$ & $\begin{array}{c}\text { SHVDC optimal } \\
\text { parameters }\end{array}$ \\
\hline$D_{m p}$ & 20 & 94.82 \\
$D_{m q}$ & 33.33 & 50.24 \\
$K_{p \_V_{d c}}$ & 5 & 15.149 \\
$K_{i V_{d c}}$ & 2 & 16.501 \\
$D_{g p}$ & 20 & 92.843 \\
$D_{g q}$ & 33.33 & 57.20 \\
$K_{p_{-} P_{g}}$ & 5 & 27.61 \\
$K_{i_{-} P_{g}}$ & 3 & 12.62 \\
\hline
\end{tabular}

The optimal parameters in the second column of Table III were obtained with (44) solved for the desired locations in Table I. The response of SHVDC for the link in Fig. 1 with these tuned parameters is given in Fig. 7 in solid lines in comparison with the ones in dotted lines obtained with a classic vector control. The active power, the voltage and the reactive power dynamics are similar which prove that the performances given in Section B.1 are correctly ensured by the proposed control methodology. Notice, however, that less overshoots with the new tuned parameters are obtained. The robustness of this approach is studied in the next section on a four machines case. 


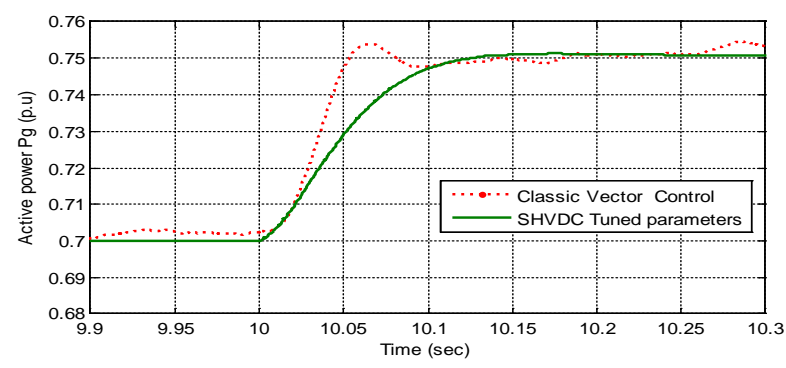

(b)

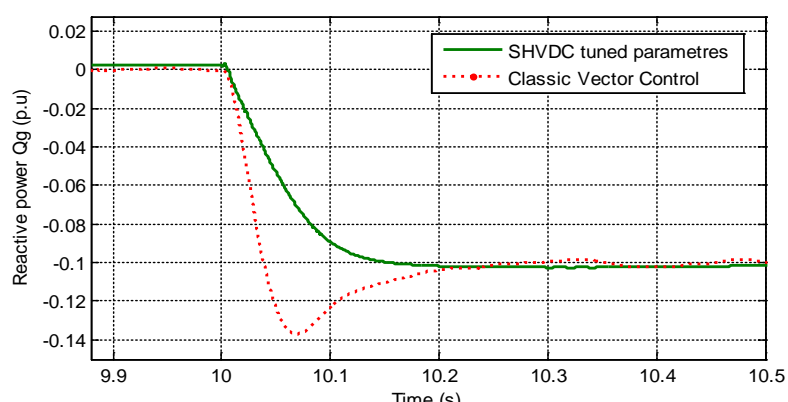

(c)

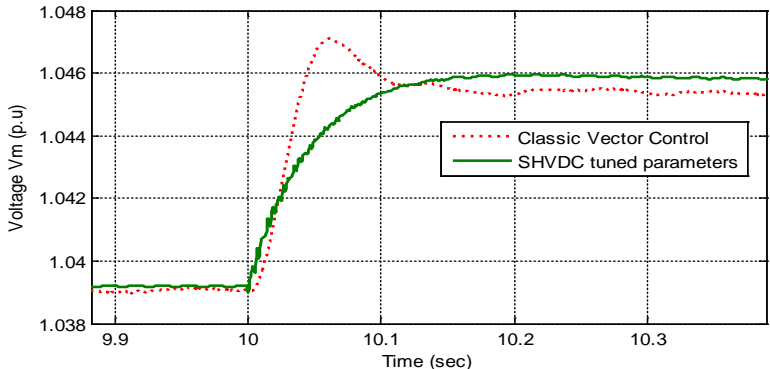

(d)

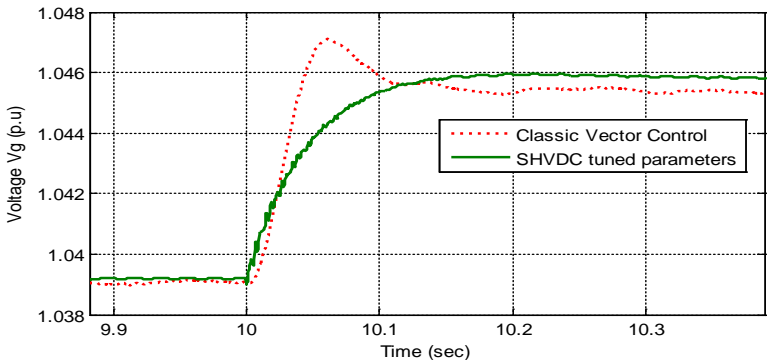

(e)

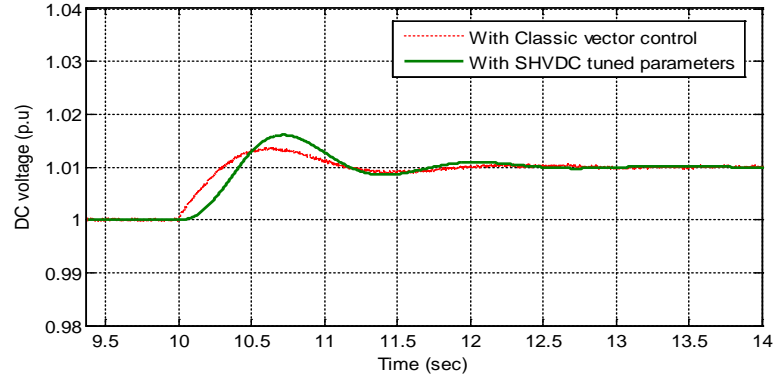

Fig. 7. Responses with optimal parameters. (a) Response of $P_{g}$ to a +0.05 step in $P_{g_{\text {rref }}}$ (p.u) ; (b) Response of $Q_{g}$ to a -0.1 step in $Q_{g_{-} \text {ref }}$ (p.u); (c) Response of $V_{g}$ to a -0.1 step change in $Q_{g_{-} \text {ref }}$ (p.u); (d) Response of $V_{m}$ to -0.1 step change in $Q_{m_{-} \text {ref }}$ (p.u); (e) Response of $V_{d c}$ to a +0.01 step in $V_{\text {dc_ref }}$ (p.u).

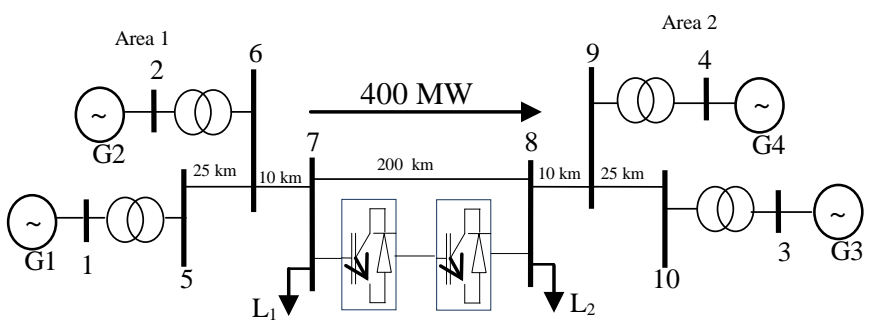

Fig. 8. Two area test system with parallel AC and DC lines

VI. Four MAchines Test POWER System

In this section, the specific tuning SHVDC parameters presented in Section $\mathrm{V}$ is tested and compared with the classic vector control on the IEEE 4 machines benchmark [15] shown in Fig. 8. The two areas are connected with an AC line in parallel with one HVDC link. The $150 \mathrm{~km}$ HVDC cable link has a rated power of $200 \mathrm{MW}$ and a DC voltage rating of $\pm 100 \mathrm{kV}$. Each area consists of two identical generating units of $400 \mathrm{MVA} / 20 \mathrm{kV}$ rating. Each of the units is connected through transformers to the $100 \mathrm{kV}$ transmission line. There is a power transfer of $400 \mathrm{MW}$ from Area 1 to Area 2. The detailed system data is given in the appendix. The loads $\mathrm{L}_{1}$ and $\mathrm{L}_{2}$ are modeled as constant impedances.

The control SHVDC approach is assessed for local performances and for transient stability. The desired HVDC performances given in Section $\mathrm{V}$ are fulfilled as shown by the step responses in Fig. 9. As for the case of the two-machine system, responses with less overshoot are obtained compared to the vector control approach.

Fig. 10 shows the response of the angular speed of generator G1 to a three phase short circuit fault of 100 ms duration, occurring in the mid-point of the AC transmission line. We can depict a better dynamic performance with the proposed controller: the transient oscillations with the SHVDC control are more damped. For the same fault, transient stability is assessed by the Critical Clearing Time (CCT), which is the maximum time duration that a short-circuit may act without losing the system capacity to recover to a steady-state (stable) operation.

The obtained CCTs for a three-phase short-circuit fault in the mid-point of the AC transmission line are presented in Table IV for the classic vector control, and the proposed SHVDC control. We can see that the SHVDC control with tuned parameters improves the transient dynamics of the system and thus augments the transient stability margins of the neighbor network. This is due to the fact that the dynamics of the neighbour zone are taken into account at the synthesis stage via the oscillatory modes in Table I. The gains of the controllers are computed to damp these modes and thus to diminish the general swing of the zone and not only for the local HVDC dynamics. Moreover, as the structure of the SHVDC mimics the closed-loop of a standard synchronous generator, an inertia with a positive impact of the transient stability of the neighbour zone is emulated. 
TABLE IV

CRITICAL CLEARING TIMES WITH BOTH CONTROL STRATEGIES

\begin{tabular}{ll}
\hline Control strategy & CCT (ms) \\
\hline Tuning SHVDC parameters & 250 \\
Classic vector control & 170 \\
\hline
\end{tabular}

(a)

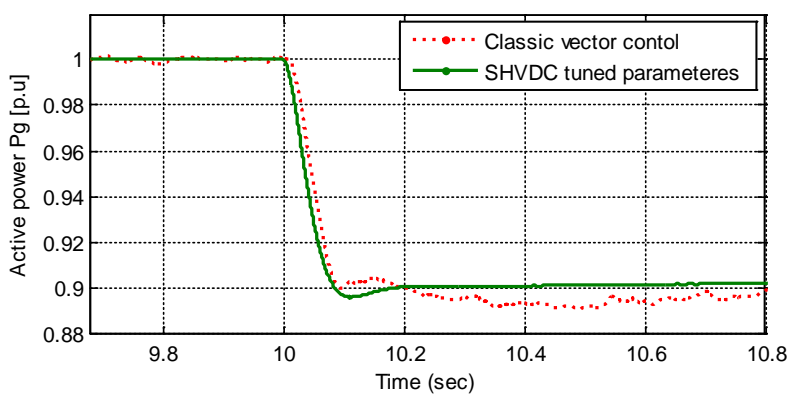

(b)

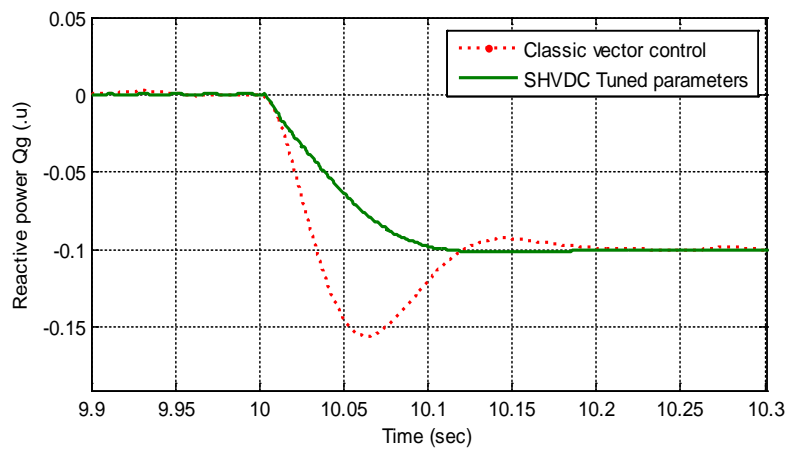

Fig. 9. Responses of the IEEE 4 machines benchmark. (a) Response of $\mathrm{P}_{\mathrm{g}}$ to a -0.1 step in $P_{\text {g_ref }}$ (p.u) ; (b) Response of $Q_{g}$ to a -0.1 step in $Q_{g \_r e f}$ (p.u).

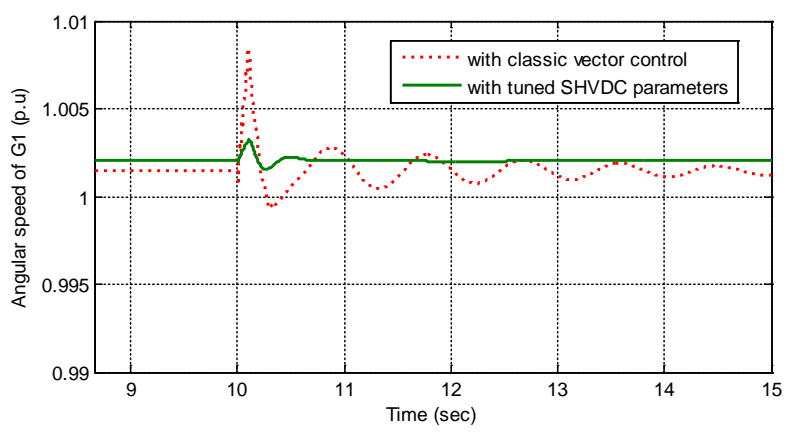

Fig. 10. Speed response of G1 to a $100 \mathrm{~ms}$ short-circuit

\section{Remark: Real-time implementation}

The SHVDC system is based on the Sinusoidal Pulse Width Modulation (SPWM) switching using a single-phase triangular carrier wave with a frequency of 27 times fundamental frequency $(1350 \mathrm{~Hz})$. This is compliant with the real time implementation which relies on a time response of 1-3 $\mu$ s [22]. Indeed, in the real time simulation, the converter stations and the connecting DC cable are simulated in three separate small time step networks [23]. The three subnetworks are connected on the DC side through travelling wave transmission line models with a travel time in the range of the small time step size (i.e. $~ 3 \mu$ s). Both converter stations are interfaced to the AC systems with the help of interfacing transformers connecting the small and the normal time step areas.

\section{CONCLUSION}

This paper proposed a new control strategy of HVDC transmission based on the synchronverter concept. The proposed synchronverter structure could not be controlled using directly the standard parameters of the SG. Thus, a specific tuning method was proposed based on; firstly, the sensitivity analysis of the system poles to the control parameters then, their placement linear approximation via residues. Better results than with the classic VSC control were obtained for the following points:

- Better dynamic performances (less overshoot and more damping) because this approach allows one to analytically take into account dynamic specifications at the tuning stage.

- Better stability margin of the neighbor zone for two reasons. First, swing information is directly taken into account at the synthesis stage in terms of the less damped modes of the neighbor zone and not only for the local HVDC dynamics as it is the case for the standard VSC control. Next, the SHVDC emulates inertia of two rotating machines and this has a direct damping effect for the neighbor zone.

- Help power system operators in system operation since the SG and their controls are better known.

It is noted that this kind of tuning is surely under optimal in the sense that the constraints to keep the structure of the classical generators and their regulations imposed by the synchronverter principle limits the performances of the resulting closed-loop. Moreover, the advantage of inertia emulation mentioned above could be lost in the context of a grid with many power electronics and few physical SG since the grid frequency is no longer (well) defined in this case.

\section{REFERENCES}

[1] D. Murali, M. Rajaram, and N. Reka, "Comparison of FACTS Devices for Power System Stability Enhancement," International Journal of Computer Applications (0975- 8887), 2010, Volume 8- No.4.

[2] F. Wang, L. Bertling, and T. Le, "An Overview Introduction of VSCHVDC: State-of-art and Potential Applications in Electric Power Systems," Cigré 2011.

[3] F. Goodrich, and B. Andersen, "The 2000 MW HVDC link between England and France," Power Eng. J., 1987, 1, (2), pp. 69-74.

[4] Y. Decoeur, "France-Spain interconnections, First step for smart grids ", inelfe, Madrid, March 26th, 2012.

[5] A.E. Hammad, J. Gagnon and D. McCallum, "Improving the dynamic performance of a complex AC/DC system by HVDC control modifications," IEEE Trans. Power Delivery, 1990, 5, (4), pp. 19341943.

[6] S. Li, T.A. Haskew, and L. Xu, , "Control of HVDC light system using conventional and direct current vector control approaches," IEEE Trans. Power Electr., 2010, 25, (12), pp. 3106-3118.

[7] H. Latorre, and M. Ghandhari, "Improvement of power system stability by using a VSC-HVDC, "Int. J. Electr. Power Energy Syst, 2011, 33, (2), pp. 332-339.

[8] N. Rostamkolai, A.G. Phadke, W.F. Long, and J.S. Thorp, "An adaptative optimal control strategy for dynamic stability enhacement of AC/DC power systems, " IEEE Trans. Power Syst., 1988, 3, (3), pp. 1139-1145.

[9] Q.-C. Zhong, and G.Weiss, "Synchronverters: Inverters that mimic synchronous generators," IEEE Trans. Ind. Electron., Apr. 2011, vol. 58, no. 4, pp. 1259-1267.

[10] L. Zhang, L. Harnefors, and H.-P. Nee, "Power synchronization control of grid-connected voltage-source converters," IEEE Trans. Power Syst, May 2010, vol. 25, no. 2, pp. 809-820.

[11] H.-P. Beck, and R. Hesse, "Virtual synchronous machine, " in Proc. of the 9th International Conference on Electrical Power Quality and Utilisation (EPQU), 2007, pp. 1-6. 
[12] J. Driesen, and K. Visscher, "Virtual synchronous generators," in Proc. of IEEE Power and Energy Society General Meeting, 2008, pp. 1-3.

[13] Y. Chen, R. Hesse, D. Turschner, and H.-P. Beck, "Improving the grid power quality using virtual synchronous machines," in 2011 International Conference on Power Engineering, Energy and Electrical Drives (POWERENG), 2011, pp. 1-6.

[14] M. Torres, and L. A. C. Lopes, "Frequency control improvement in an autonomous power system: An application of virtual synchronous machines," in 2011 IEEE $8^{\text {th }}$ International Conference on Power Electronics and ECCE Asia (ICPE \& ECCE), 2011, pp. 2188-2195.

[15] P. Kundur, "Power system stability and control", Mc Graw-HillInc, 1994.

[16] P-L. Nguyen, Q-C. Zhong, F. Blaabjerg, and J-M. Guerrero, " Synchronverter-based Operation of STATCOM to Mimic Synchronous Condensers", 2012 7th IEEE Conference on Industrial Electronics and Applications (ICIEA).

[17] H. Bourlès, and B. Marinescu, "Linear-Time Varying Systems, Algebraic-Analytic Approach", Springer-Verlag, LNCIES 410, 2011.

[18] IEEE Recommended Practice for Excitation System Models for Power System Stability Studies, IEEE Power Engineering Society, 21 April 2006.

[19] S. Li, T.A. Haskew, L. Xu, "Control of HVDC light system using conventional and direct current vector control approaches", IEEE Trans. Power Electr., 2010, 25, (12), pp. 3106-3118.

[20] M-K-S. Sangathan, J- Nehru "Performance of high-voltage direct Current (HVDC) systems with Line-commutated converters", bureau of find Indian standard Manak Bhavan, 9 Bahadur Shah Zafar Marg New Delhi 110002 , April 2013.

[21] G. Rogers, "Power System Oscillations", Kluwer Academic, 2000.

[22] P.A. Forsyth, T.L. Maguire, D. Shearer, D. Rydmell, ' Testing Firing Pulse Controls for a VSC Based HVDC Scheme with a Real Time Timestep < $3 \mu \mathrm{s}$ ", the International Conference on Power Systems Transients (IPST2009) in Kyoto, Japan June 3-6, 2009.

[23] Pinaki Mitra, Vinothkumar K , Lidong Zhang, ' Dynamic Performance Study of a HVDC Grid Using Real-Time Digital Simulator”, IEEE Workshop on Complexity in Engineering 11 June, Aachen, Germany 2012.

\section{APPENDIX}

Network data (Fig. 1)

Bus system 1 \& 2: line voltage $=100 \mathrm{kV}$, frequency $=50 \mathrm{~Hz}$, Short circuit power $=600 \mathrm{MVA}, \mathrm{Rs}=0.75 \Omega, \mathrm{Ls}=0.2 \mathrm{H}$

27th AC filter in AC system 1 \& 2: reactive power=18 MVAR, tuning frequency $=1620 \mathrm{~Hz}$, quality factor $=15$.

54th AC filter in AC system 1 \& 2: reactive power=22 MVAR, tuning frequency $=3240 \mathrm{~Hz}$, quality factor $=15$.

DC system: voltage $= \pm 100 \mathrm{kV}$, rated DC power $=200 \mathrm{MW}$, Pi line $\mathrm{R}=0.0139$ $\Omega / \mathrm{km}, \mathrm{L}=159 \mu \mathrm{H} / \mathrm{km}, \mathrm{C}=0.331 \mu \mathrm{F} / \mathrm{km}$, Pi line length $=150 \mathrm{~km}$, switching frequency $=1620 \mathrm{~Hz}$, DC capacitor $=70 \mu \mathrm{F}$, smoothing reactor: $\mathrm{R}=0.0251 \Omega$, $\mathrm{L}=8 \mathrm{mH}$.

Parameters of the classic vector control: current loop: $\mathrm{kp}=0.6, \mathrm{ki}=6$, reactive power control: $\mathrm{ki}=20$, active power control: $\mathrm{ki}=20$, DC voltage control: $\mathrm{kp}=5$, $\mathrm{ki}=2$.

Network data (Fig. 8)

Generators: Rated 400 MVA, $20 \mathrm{kV}$

$\mathrm{Xl}$ (p.u): leakage Reactance $=0.18$

Xd (p.u.): d-axis synchronous reactance $=1.305, T^{\prime} d 0(s)$ : d-axis open circuit sub-transient time constant $=0.296$, $\mathrm{T}$ 'd0 $(\mathrm{s})$ : $\mathrm{d}$-axis open circuit transient time constant $=1.01$

Xq (p.u): q-axis synchronous reactance $=0.053, \mathrm{Xq}(\mathrm{p} . \mathrm{u})$ : q-axis synchronous reactance $=0.474, X$ ' 'q (p.u): q-axis sub-transient reactance $=0.243$, T' 'q0 (s): q-axis open circuit sub transient time constant $=0.1$

$\mathrm{M}=2 \mathrm{H}(\mathrm{s})$ : Mechanical starting time $=6.4$

Governor control system

$R(\%)$ : permanent droop $=5$, servo-motor: $\mathrm{ka}=10 / 3$, ta $(\mathrm{s})=0.07$, regulation

PID: $\mathrm{kp}=1.163, \mathrm{ki}=0.105, \mathrm{kd}=0$

Excitation control system

Amplifier gain: $\mathrm{ka}=200$, amplifier time constant: $\mathrm{Ta}(\mathrm{s})=0.001$, damping

filter gain $\mathrm{kf}=0.001$, time constant te $(\mathrm{s})=0.1$

27th AC filter in AC system 1 \& 2: reactive power=18 MVAR, tuning

frequency $=1620 \mathrm{~Hz}$, quality factor $=15$.

54th AC filter in AC system 1 \& 2: reactive power=22 MVAR, tuning

frequency $=3240 \mathrm{~Hz}$, quality factor $=15$.
DC system: voltage $= \pm 100 \mathrm{kV}$, rated DC power $=200 \mathrm{MW}$, Pi line $\mathrm{R}=0.0139$ $\Omega / \mathrm{km}, \mathrm{L}=159 \mu \mathrm{H} / \mathrm{km}, \mathrm{C}=0.331 \mu \mathrm{F} / \mathrm{km}$, Pi line length $=150 \mathrm{~km}$, switching frequency $=1620 \mathrm{~Hz}, \mathrm{DC}$ capacitor $=70 \mu \mathrm{F}$, smoothing reactor: $\mathrm{R}=0.0251 \Omega$, $\mathrm{L}=8 \mathrm{mH}$.

Generator transformers Rated 400 MVA, 20/ 100 kV

Coupling Delta/ Yg

Primary resistance (p.u) $=0.002$, Primary inductance (p.u) $=0.12$

Secondary resistance (p.u) $=0.002$, Secondary inductance (p.u) $=0.12$

Loads: PL1=200 MW, PL2=1GW

AC transmission lines

Resistance per phase $(\Omega / \mathrm{km})=0.03$

Inductance per phase $(\mathrm{mH} / \mathrm{km})=0.32$

Capacitance per phase $(\mathrm{nF} / \mathrm{km})=11.5$

Parameters of the classic vector control: current loop: $\mathrm{kp}=0.6, \mathrm{ki}=8$, reactive power control: $k i=40$, active power control: $k i=40$, DC voltage control: $k p=1$, $\mathrm{ki}=10$. 